\title{
MODELLING OF TRANSPORT OPERATIONS IN SUPPLY CHAINS IN OBEDIENCE TO "JUST-IN-TIME" CONCEPTION
}

\author{
Valery LUKINSKIY' ${ }^{1}$, Vladislav LUKINSKIY², Yuri MERKURYEV ${ }^{3}$ \\ ${ }^{1}$ Dept of Logistics and Supply Chain Management, National Research University Higher School of Economics, \\ Saint Petersburg, Russia \\ ${ }^{2}$ Dept of Management, National Research University Higher School of Economics, Saint Petersburg, Russia \\ ${ }^{3}$ Dept of Modelling and Simulation, Riga Technical University, Latvia
}

Received 3 May 2016; revised 13 September 2016, 27 December 2016; accepted 4 February 2017

\begin{abstract}
Transportation is a key logistics function, which determines the dynamic nature of material flows in logistics systems. At the same time, transportation is a source of uncertainty of logistics operations performance in the supply chain. Obviously, the development of a new approach for evaluation of the duration of delivery "Just-In-Time" (JIT) will improve the efficiency of supply chains in accordance with one of the major criteria, namely customer satisfaction. One of the basic approaches to make effective management decisions in transportation and other logistic operations is the JIT concept. In the majority of examined sources the JIT concept is described on the verbal level without any usage of calculation dependences. The paper is devoted to the formation of analytical and simulation models, which allow obtaining the probabilistic evaluation of the implementation of unimodal and multimodal international transportation JIT. The first model where the order of the operations implementation does not affect final result is formed on the basis of the probability theory: distribution laws composition, theorems of numerical characteristics of random variables, formula of complete probability. The second model accounts the impact of operations implementation order in transportation and their interconnection and is based on the simulation (the method of statistic experiments) and shown as a corresponding algorithm, which allows to consider different limitations (technical, organizational and so on). Considered analytical dependences give the possibility to obtain the necessary estimations of the transport operations implementation according to JIT: mean transportation time, delivery implementation probability by the set moment or the delivery time with the set probability. To carry out some comparative calculations and clarify the algorithm, two international routes have been chosen: the first one is a unimodal road transportation, the second one is a multimodal transportation (road and marine transport). All the data, which is necessary for calculation has been collected on the basis of official information (in particular, the data of tachograph, special questionnaires filled in by the drivers, the survey results of the managers). For unimodal transportations analytical dependences and modelling results give close results. For the combined multimodal transportations taking into account various limitations the preference must be given to the simulation. The modelled indexes take into consideration their intercommunication and definitely estimate the supply chains reliability, and this allows decreasing the uncertainty of the logistic system.
\end{abstract}

Keywords: logistics, probability, reliability, scheduling, simulation, transportation.

\section{Introduction}

The necessity of forming some new approaches to the increase of organizationally-economic stability of companies, maintenances of their competitiveness and the efficiency of functioning is conditioned by strengthening of competition in different industries, by growing dynamism of environment of companies prevailing of the idea of "buyers market". One of the methods of permission of the indicated problems is the realisation of logistic prin- ciples in management by both separate companies and supply chains. There are various logistic definitions, for example, "logistics is defined as the process of planning, implementing, and controlling procedures for the efficient and effective transportation and storage of goods including services and related information conforming to customer requirements" (Huber et al. 2015). In the article by Vasilis Vasiliauskas and Jakubauskas (2007) it is noted that

*Corresponding author. E-mail: lukinskiy@mail.ru 
"logistics has been called the last frontier that even at the present time, the improvement of logistics has been the primary source of companies' to make new profits and maintain competitive advantage".

It's marked in the work by Stadtler and Kilger (2008) that "no longer companies but whole supply chains compete against each other", wherein "supply chains are becoming more and more global" (Bazaras et al. 2015). In this way the time of order execution problem is getting more and more important, so it was examined in the book by Christopher (2016): "most organizations face a fundamental problem: the time it takes to procure, make and deliver the finished product to a customer is longer than the time the customer is prepared to wait for it".

The importance of transportation, variety of solutions and influence of accurate delivery time observance on other participants of supply chains are also emphasised in works of many authors. "Nowadays transport systems provide both support for economic development and social equality. Sustainable development of transport systems requires the ability to measure the quality of services provided by transport systems" (Yatskiv et al. 2012). "Transportation can take the form of many combinations of modes and routes, each with its own performance characteristics. Transportation choices have a large impact on supply chain responsiveness and efficiency" (Chopra, Meindl 2015). "Carriage of containers, in combination of sea and rail transport, is becoming more and more popular" (Palšaitis, Ponomariovas 2012). "Transport schedule can be defined in different ways, for example a cargo ought to be delivered to the node before the end of fixed timeperiod, because a train cannot wait for a truck with the cargo" (Mazurkiewicz, Walkowiak 2013). "If the train arrives late at the railway stations, the trucks probably reach the stores too late as well. This means that the employees who pick up the products in the shops have to wait and as a consequence working hours are lost" (Krüger, Vierth 2015).

Nowadays there are a lot of complicated problems facing the transportation enterprises, and logistic, particularly "Just-In-Time" (JIT) concept, can help to solve them. Here are some of them. "Striving for attracting a larger number of clients, enterprises involved in rendering transport services should, first of all, care about improvement of a reliability of the service and the reputation of the enterprise" (Lazauskas et al. 2012). "Changes in freight transport are mainly driven by logistics concepts (e.g., sourcing, consolidation and distribution of goods)" (Huber et al. 2015). "There have been many new ideas and concepts in business management over the last 30 or so years, some of which have endured and others soon discarded. However, perhaps one of the most significant principles to become widely adopted and practised is that of JIT" (Christopher 2016). "Compressing the time between when customer orders are placed and when they are received can be a competitive advantage. This Quick Response (QR) is based in many of the same ideas behind JIT scheduling" (Ballou 2003).
According to some specialists, road transportation plays a special role in transportation, for instance: "motor carriers provide a vital function in modern societies, and their importance is likely to grow with the increasing customer requirements for better service and reduced cycle times" (Langevin, Riopel 2005).

In the most of examined works the JIT concept is described on the verbal level without using calculation dependences. "With JIT, materials arrive where they are needed only when they are needed. Ideally, in a JIT environment, order size is one and single units are being pulled from one adjacent process to another. More realistically, analysis of the process, transportation time, and containers used for transport are considered when determining lot size" (Heizer et al. 2016). "Reducing the order quantity for an item reduces the cycle inventory held in storage while increasing the number of order per year. The ultimate is a JIT, where orders of small quantities are placed as they needed" (Krajewski et al. 2015). "JIT, as practiced by Japanese, is more comprehensive than an inventory management system. It includes a comprehensive culture of quality, vendor partnerships, and employee teams" (Coyle et al. 2002). "An entire assembly plant may be forced to shut down if a certain component is not delivered at the agreed time" (Jonsson 2008).

Many authors note the tight connection between the JIT and other logistic concepts. "The last few decades has seen the introduction of Flexible Manufacturing Systems (FMS), of new approaches to inventory based on Materials Requirements Planning (MRP) and JIT methods and, perhaps most important of all, a sustained emphasis on Total Quality Management (TQM)" (Christopher 2016). "In the 1990s, Supply Chain Management (SCM) emerged as the paradigm that combined several strategies already in use, including QR, Efficient Consumer Response (ECR), JIT and Japanese keiretsu relationships" (Wisner et al. 2004). "An MRP system combined with JIT can provide the best of both worlds. MRP provides the plan and an accurate picture of requirements; then JIT rapidly moves material in small batches, reducing work-in-process inventory" (Heizer et al. 2016).

It should be pointed out that the opinion about expediency of JIT concept introduction in any supply chains is controversial. "Some mention should also be made of the fact that not all JIT systems have been successfully implemented, nor can JIT be used in every situation. Successful implementation of JIT requires an integrated, coordinated effort among several functions in a company and members of the supply chain" (Coyle et al. 2002). "Companies who thought they could achieve a leaner operation by moving to JIT practices often only shifted costs elsewhere in the supply chain by forcing suppliers or customers to carry that inventory... JIT practices were widely adopted and organizations became increasingly dependent upon suppliers" (Heizer et al. 2016).

Even a wider circle of issues is raised in work (Krajewski et al. 2015): "Supply chains often pose ethical issues for their managers... Imagine a large metropolitan area where 
most businesses are using JIT system and the traffic congestion that results from delivery trucks carrying the small order quantities. While the cost for the inventory system for the given company is minimized in the traditional sense, noise pollution, energy consumption, air pollution, and travel time have increased for the community at large".

The analysis of different sources on logistic and SCM has shown (Lukinskiy et al. 2007) that the following conclusions can be drawn:

- there is no unambiguous interpretation for the JIT notion either in logistics or in SCM;

- most scientists and specialists examine the JIT notion at the conceptual or semantic level (without the quantitative estimation of indexes);

- many terms of JIT concept are used in other industries as synonyms: QR, Lean Production (LP), ECR; Continuous Replenishment Planning (CRP) and others.

The undertaken studies have shown that the sources of uncertainty are the random values, which are connected with the executing next five operations of a logistic cycle: transmission of order, order processing and acquisition of order, transportation and delivery to the consumer. "The lead-time is the time from the ordering decision until the ordered amount is available on shelf. It is not only the transit time from an external supplier or the production time in case of an internal order. It is also includes, for example, order preparation time, transit time for the order, administrative time at the supplier, and time for inspection after receiving the order" (Axsäter 2015). "Delivery time is the time that elapses from a customer order being received to completed delivery. It consists of administration and order processing times, dispatch and transport times and, in the case of engineer or make to order, engineering or manufacturing times" (Jonsson 2008).

To make the quantitative evaluation of the duration of logistic operations implementations according to the JIT concept it is offered to use the following approaches. "The routes can be distinguished in terms of actual travel times and time reliability (variance of actual travel times)" (Bifulco et al. 2014). "Travel time distribution or variability in travel time is the most useful indicator to measure the performance and reliability of a transportation system" (Chalumuri, Yasuo 2014).

The importance of the correct calculations of the JIT model parameters is noted in a range of works. "Long delivery times have many negative consequences; among these, decreased flexibility due to extended response times for the order. Capital tied up and its associated costs also increase since the materials are in transit for a longer period" (Jonsson 2008). "Vehicles during the transportation process cause some negative effects such as delay, damaging of the load, drivers or other road users" (Palšaitis, Petraška 2012; Petraška 2017, 2018). "Transportation delays decrease production, increase inventory costs, and disrupt operations, which defeats JIT's objectives" (Coyle et al. 2002).

In Table 1 there are some generalised results of JIT concept research (Bowersox, Closs 1996; Kersten, Blecker 2006; Lukinskiy et al. 2014; Stock, Lambert 2000) carried out from the view point of application of basic indexes and their quantitative estimations.

From Table 1 we can conclude the following:

- according to the JIT concept quantitative and probabilistic indexes can be used to estimate transport operations. In this case every index is examined as an independent criterion;

- the question of interconnection between the values of temporal and probabilistic indexes is still unanswered because the function of delivery terms distribution has not been brought about;

- the greatest uncertainty is typical for transportation and it is typical for customer delivery operation in less degree. It is well known that transportation

Table 1. JIT model indexes

\begin{tabular}{|c|c|c|}
\hline $\begin{array}{l}\text { Types of uncertainty } \\
\text { situations in SC }\end{array}$ & Functioning indexes & Examples of indexes actual values \\
\hline \multirow{3}{*}{ Reliability estimation } & $\begin{array}{l}\text { Delivery of commodity to the } \\
\text { client }\end{array}$ & Delivery time $-1 \mathrm{~h}$; probability of transportation faultlessness -0.95 \\
\hline & Total delivery time & $\begin{array}{l}\text { Not more than } 24 \mathrm{~h} \text { for A-class goods (ABC inventory management } \\
\text { method); not more than } 96 \mathrm{~h} \text { for C-class goods (ABC inventory } \\
\text { management method) }\end{array}$ \\
\hline & Admissible delivery delay & $\begin{array}{l}\text { In ban interval of } 0.25 \ldots 0.50 \mathrm{~h} \text {; delivery probability } \\
\text { in the set interval }-0.985\end{array}$ \\
\hline \multirow{2}{*}{$\begin{array}{l}\text { Estimation of logistic } \\
\text { cycles duration of } \\
\text { "physical distribution" } \\
\text { and "supply" }\end{array}$} & $\begin{array}{l}\text { The duration of separate } \\
\text { constituents }\end{array}$ & $\begin{array}{l}\text { An order }(0.5 \ldots 3 \text { days }) \text {; order processing ( } 1 \ldots 4 \text { days); completing or } \\
\text { production }(1 \ldots 20 \text { days); transportation ( } 1 \ldots 10 \text { days); delivery } \\
(0.5 \ldots 3 \text { days })\end{array}$ \\
\hline & Whole cycle duration & From 3.5 till 40 days \\
\hline \multirow{2}{*}{$\begin{array}{l}\text { Key performance } \\
\text { indicators (KPI) } \\
\text { determination, supply } \\
\text { chain operations } \\
\text { reference (SCOR) model }\end{array}$} & $\begin{array}{l}\text { Metrics: execution of delivery } \\
\text { to the certain term }\end{array}$ & $\begin{array}{l}\text { The actual value for the company (90\%); average data in the branch } \\
(75 \%) \text {; competitor index value }(87 \%) \text {; leader index value }(95 \%) \text {. }\end{array}$ \\
\hline & Metrics: delivery time & $\begin{array}{l}\text { The actual value for the company ( } 1 \ldots 4 \text { days); average data in the } \\
\text { branch ( } 2 \text { days); competitor index value ( } 1 \text { day); leader index value } \\
\text { ( } 1 \text { days) }\end{array}$ \\
\hline
\end{tabular}


operations in global (international) and internal supply chains differ significantly. For example, in work (Bowersox, Closs 1996) is said that, if at the internal market the transit time varies from 3 to 5 days and the whole functional cycle takes from 4 to 10 days, at the international level the functional circle sometimes makes even weeks or months;

- final distribution function, which is a sum of random variables has asymmetric character and it is very important to take this into consideration while estimating supply chains reliability;

- all the examined types of the uncertainties are closely connected and therefore the problems with the estimation of the duration of logistic operations and functions implementation are identical.

Thus, the following conclusions can be drawn:

- the sources of the uncertainty are the random values, which are connected with the implementation of the following operations of logistic cycle: transmission of order, processing, acquisition of order (production), transportation and delivery to the final consumer;

- it is considered that while making administrative decisions the most difficult for quantitative estimation are those operations, which are connected with multimodal (combined) transportations;

- to solve the tasks for uncertainty reduction in supply chains the JIT model and its modifications are considered to be the most perspective ones;

- as most specialists regard the JIT notion at the conceptual level, and individual attempts to take conceptual approach to the calculation model have not found a wide use, it has become necessary to develop a new methodical approach for the quantitative estimation of transportation process.

The purpose of the article is to form models, which allow calculating probabilistic evaluations of time durations of transportation operations execution in supply chains, particularly, unimodal and multimodal transportations according to the JIT concept. It is shown that for the analytical description of a transportation process two models can be used. The first model, where the order of the operations implementation does not affect the final result, is formed on the basis of the probability theory: distribution laws composition, theorems of numerical characteristics of random variables, formula of complete probability. The second model considers the impact of operations implementation order in transportation and their interconnection and it is based on the simulation (method of statistic experiments) and is shown as a corresponding algorithm, which allows considering various limitations (technical, organizational and so on).

Developed models approbation has been executed on the basis of collected and systematized data of some transport-logistic companies, and it proves the possibility of their usage as a reliable and true basis for making effective transportation management decisions.

\section{Transportation model formation under the JIT concept}

As it was said before, the transportation operations are the most difficult while preparing and making decisions about supply chains management. These operations are characterised by a big number of indexes and factors. It happens this way because the environment of these operations is characterised by the uncertainty, which in return is attended with various in nature and frequency risks. The modes of transport (road, marine and other ones) and the type of transportation (direct, mixed, unimodal, multimodal one and so on) relate to the main classification signs of transportation.

While developing the transportation model the main attention has been paid to the road transport that does not belittle importance of other modes in any way.

Temporal descriptions of overcoming difficult situations in the International Road Transportations (IRT) and observances of requirements to this type of transportations have random character, and it is really important to take this character into account while designing the cargo delivery, planning and organising transportations JIT. The basic source of chance is a route, which is characterised by a certain extent, a type of road coverage, country limitations and other parameters.

From the point of view of organizational, technological and administrative aspects, IRT are a more difficult process comparing to the transportations within one country. The difficulty of the international transportations is caused by the necessity to cross the borders and custom regulation of goods traffics, the features of national documents circulation, inspection verifications of the technical state of transport vehicles, the observance of weigh-size and ecological limitations, the necessity of observance of drivers labour and rest mode and other circumstances (Christopher 2016; Ge et al. 2015; Bowersox, Closs 1996; Petraška et al. 2017, 2018; Chopra, Meindl 2015).

According to (Lukinskiy et al. 2007), in a general case, the constituents of vehicular process are random values. Therefore, a quantitative estimation must be done with the use of probabilistic descriptions.

Taking into account the enumerated features the time of transportation during the working day can be defined with the help of the following formula:

$$
T_{o}=\sum_{i=1}^{A} t_{i, i+1}+\sum_{j=1}^{B} \tau_{j}+\sum_{k=1}^{C} \Theta_{k},
$$

where: $t_{i, i+1}$ is the travelling time between $i$-th and $(i+1)$-th points; $\tau_{j}$ is the time of the customs documents preparation in $j$-th point (in the country and at the borders); $\Theta_{k}$ is the time for loading, unloading and warehousing in $k$-th point; $A, B, C$ are the number of road sections a vehicle moves, customhouses and loading/unloading points, accordingly.

Formula (1) reflects continuous time of a vehicle being in a line at implementation of this journey, but it doesn't completely take into account the specific of inter- 
national transportations, which is conditioned: firstly, by limitation of labour and rest mode of a driver or a vehicle crew according to European Agreement Concerning the Work of Crews of Vehicles Engaged in International Road Transport (Accord Européen sur les Transports Routiers AETR); secondly, by the heavy vehicle driving limitations in the territory of some countries on working days and on the days-off (for example Germany); thirdly, by the necessity to carry out the repair-prophylactic works, in particular, by the removal of failures, and also by other reasons of outage on a route, by the road police checking the axis load, that is a part of a period of productive activity of driver during a working day apart from driving.

Taking into account the specific of international transportations, formula (1) must be corrected and presented in the following form:

$$
\begin{aligned}
& T_{o}=\sum_{i=1}^{A} t_{i, i+1}+\sum_{j=1}^{B} \tau_{j}+\sum_{k=1}^{C} \Theta_{k}+ \\
& \sum_{l=1}^{D} \varphi_{l}+\sum_{m=1}^{E} \psi_{m}+\sum_{n=1}^{F} \eta_{n},
\end{aligned}
$$

where: $\varphi_{l}$ is a random constituent that reflects the increase of transportation time caused by the delays for carrying out the repair-prophylactic works and other reasons; $\psi_{m}$ is a random constituent that reflects limits on a route connected the driver labour and rest mode; $\eta_{n}$ is a random constituent that reflects the heavy vehicle driving limitations; $D, E, F$ are the number of cases of vehicle outage taking into account the indicated reasons, accordingly.

While forming model (2), the features, related to the accumulation of driver working time during a day, week and two weeks, are taken into account that results in the increase of the transportation time without the change of the way passed. It stipulates the necessity to include the variable $\psi_{m}$ into the model. A further specification requires the introduction to the model of three inequalities that is restrictions for limitations for every day of vehicle traffic during the transportation time. The first one reflects the vehicle driving time:

$$
\sum t_{i, i+1}<T_{d} \text {, }
$$

where: $T_{d}$ is rationed duration of driving time in a day (for example $9 \mathrm{~h}$ ).

The second inequality is related to duration of daily rest $T_{r}$ :

$$
\sum\left(t_{i, i+1}+\Theta_{k}+\tau_{j}+\varphi_{l}+\eta_{n}\right)<24-T_{r} .
$$

This condition means that, for example, at $T_{r}=11 \mathrm{~h}$ the total duration of all transport-logistic operations cannot exceed $13 \mathrm{~h}$.

Finally, the third inequality reflects situational character of models (1) and (2) and it is related to a driver making daily decision about driving continuation or stop for the rest in the point of $N$ :

$$
\left(T_{w}-\sum_{i=1}^{N} T_{i-1, i}\right) \leq \bar{T}_{i, i+1},
$$

where: $\sum_{i=1}^{N} T_{i-1, i}$ is the accumulated time of transportlogistic operations implementation to the point of $\mathrm{N}$; $\bar{T}_{i, i+1}$ is the mean time of the next operation implementation; $T_{w}$ is the mean time of a driver working day $\left(T_{w}=24-T_{r}=13 \mathrm{~h}\right)$.

If condition (5) is not observed, then a next operation is executed, for example, custom passing, loading etc.

We will use the formula of complete probability to form a function of probability distribution of transportation implementation time:

$$
F_{\Sigma}(T)=\sum P\left(H_{i}\right) \cdot F\left(T \mid H_{i}\right),
$$

where: $P\left(H_{i}\right)$ is the probability of $i$-th event (hypotheses); $F\left(T \mid H_{i}\right)$ is a function of time distribution of transport-logistic operations implementation according to the $i$-th hypotheses.

As the first hypothesis we will accept that traffic submits to dependence (1), that is without delays or limitations. As a second hypothesis $H_{2}$ we will accept that that the traffic submits to dependence (2) and there is one delay, the hypothesis $\mathrm{H}_{3}$ has two delays and so on.

It is obvious that one of the possible variants for the calculation of hypotheses probability of $P\left(H_{i}\right)$ is to use the discrete distributions, for example, binomial or Poisson. There is another variant and to calculate $P\left(H_{i}\right)$ we have to use a general theorem about the repeated experiments.

Let us define the time for the transportation beginning $T_{b}$ on the basis of $T_{o}$ :

$$
T_{b}=T_{J I T}-T,
$$

where: $T_{I I T}$ is the time of delivery according to JIT.

The $T_{b}$ time is necessary to synchronise and coordinate the vehicle driving time and the calendar time in accordance to which the work of other transport (for example ferries) or terminals (warehouses) etc. is scheduled.

Taking into account that mean driver's working daytime at the IRT implementation is equal to $T_{w}$, then calendar duration of transportation can be calculated with a formula:

$$
D_{w}=\frac{T_{o}}{T_{w}} .
$$

It is necessary to underline that firstly, analogical formulas, which consider specific features can be used for timing of transportation by other modes of transport; secondly, acquired formulas where $t_{i, i+1}$ and $\Theta_{k}$ are taken into account allow us to estimate the transportations implementation time within one country; thirdly, while considering the combined transportations, for example, road and marine transport, certain elements are entered in formulas that reflect the specific of corresponding transport mode.

Thus, this formed model, which includes dependences (1)-(8) allows us to estimate transportation operations implementation from the JIT concept point of view. 


\section{Analytical dependences for delivery timing}

According to the formed model the estimation of density $f_{\Sigma}(t)$ and the function of delivery time distribution $F_{\Sigma}(T)$ can be introduced as a sum of random variables of $T_{i}$ that is:

$$
T=t_{1}+t_{2}+\ldots+t_{n}=\sum_{i=1}^{n} t_{i}
$$

It is known that the law of distribution of the sum of independent random values is called "a composition".

If $x$ and $y$ are the independent non-negative random values with the density distribution of $f_{1}(x)$ and $f_{2}(y)$, then the formula to calculate density distribution for a random value of $z=x+y$ is written down like (the formula of "reduction" of the $f_{1}(x)$ and $f_{2}(y)$ functions):

$$
f(z)=\int_{0}^{z} f_{2}(z-x) \cdot f_{1}(x) d x=\int_{0}^{z} f_{1}(z-y) \cdot f_{2}(y) d y .
$$

Formulas of two random values composition are brought in Table 2.

Composition of several random values distribution is calculated by the repeated use of the reduction formula.

The row of works analysis has shown that the calculation dependences for $f_{\Sigma}(T)$ are obtained only for several distribution laws with different parameters. They are the Normal, Exponential and Poisson distributions (Table 3).

The probability estimation of JIT delivery is calculated by the formula:

$$
P(T)=\int_{0}^{T_{0}} f_{\Sigma}(T) d T
$$

For instance, in the case of normal distribution laws the formula for $P(T)$ will be written down as:

$$
P(T)=\Phi\left(\frac{T_{0}-T_{\Sigma}}{\sigma_{\Sigma}}\right)
$$

where: $T_{\Sigma}=\sum_{i=1}^{n} \bar{t}_{i} ; \sigma_{\Sigma}^{2}=\sum \sigma_{i}^{2} ; \Phi(x)$ is a normal distribution function (Ventcel', Ovcharov 1983).

Another approach to calculate the statistic parameters of transportation time $T_{o}$ is based on the theorems about the numerical characteristics of the random variables. Thus, the mean value of the random variables sum is calculated by the formula:

$$
M\left[\sum t_{i}\right]=\sum_{i=1}^{n} M\left[t_{i}\right],
$$

dispersion with taken into account correlation of random variables of $t_{i}$ :

$$
D\left[\sum t_{i}\right]=\sum_{i=1}^{n} D\left[t_{i}\right]+2 \cdot \sum_{i<j} K\left(t_{i}, t_{j}\right) .
$$

In literature, for instance, Ventsel, Ovcharov (1983), there are also formulas for the third and fourth central moments.

One of the variants to define the kind of the distribution laws $F_{\Sigma}(T)$ is to use the variation coefficient. After the verification of distribution law choice rightness on the basis of goodness criteria is done, the following step is taken. It is the probability calculation $P(T)$ by formula (11).

Considered analytical dependences allow us to obtain the necessary estimations of the transport operations implementation according to JIT: mean transportation time, delivery implementation probability by the $T_{o}$ moment or the delivery time with the set probability. The adequacy of the obtained estimations will depend on the limitations number and their values. Nevertheless, the presented formulas can be applied at the stages of supply chains modelling and in the case of their reengineering.

Table 2. Formulas to calculate the distribution density $f(z)$ of two random values $x$ and $y$

\begin{tabular}{|l|l|l|}
\hline \multicolumn{1}{|c|}{ Distribution law $f(x)$, parameter(s) } & Distribution law $f(y)$, parameter(s) & Density of the distribution $f(z)$ \\
\hline 1. Normal, $m_{x}, \sigma_{x}$ & Normal, $m_{y}, \sigma_{y}$ & $f(z)=\frac{1}{\sqrt{2 \pi} \cdot \sqrt{\sigma_{x}^{2}+\sigma_{y}^{2}} \cdot \exp \left(-\frac{\left(z-m_{x}-m_{y}\right)^{2}}{2 \cdot\left(\sigma_{x}^{2}+\sigma_{y}^{2}\right)}\right)}$ \\
\hline 2. Exponential, $\lambda$ & Exponential, $\lambda$ & $f(z)=\lambda^{2} \cdot z \cdot \exp (-\lambda \cdot z)^{*}$ \\
\hline 3. Exponential, $\lambda_{1}$ & Exponential, $\lambda_{2}$ & $f(z)=\frac{\lambda_{1} \cdot \lambda_{2}}{\lambda_{1}-\lambda_{2}} \cdot\left(\exp \left(-\lambda_{1} \cdot z\right)-\exp \left(-\lambda_{2} \cdot z\right)\right)^{* *}$ \\
\hline 4. Chi-squared distribution, $k$ & Chi-squared distribution, $m$ & $f(z)=\frac{z^{2}}{2} \cdot \exp \left(\frac{-z}{2}\right)$ \\
& Poisson, $b$ & where $p=k+\frac{p}{2} \cdot \Gamma\left(\frac{p}{2}\right)$ \\
\hline 5. Poisson, $a$ & $p(z)=\frac{1}{z !} \cdot(a+b)^{z} \cdot \exp (-(a+b))$ \\
\hline
\end{tabular}

Notes: ${ }^{*}$ - Erlang law of the second order; ${ }^{*}$ - generalized Erlang law. 
Table 3. Formulas for calculation the sum distribution density of several random values

\begin{tabular}{|l|l|l|}
\hline \multirow{2}{*}{$\begin{array}{c}\text { Distribution law, } \\
\text { parameter(s) }\end{array}$} & \multicolumn{2}{|c|}{ Distribution density } \\
\cline { 2 - 4 } Normal, $m, \sigma$ & $f_{n}(Z)=\frac{1}{\sigma \cdot \sqrt{2 \cdot \pi \cdot n} \cdot \exp \left(-\frac{(Z-n \cdot m)^{2}}{2 \cdot n \cdot \sigma^{2}}\right)}$ & $f_{n}(Z)=\frac{1}{\sqrt{2 \cdot \pi} \cdot D} \cdot \exp \left(-\frac{(Z-M)^{2}}{2 \cdot D}\right)$, \\
\hline Exponential, $\lambda$ & $f_{n}(Z)=\frac{Z^{m-1} \cdot \lambda^{m}}{(m-1) !} \cdot \exp (-\lambda \cdot Z)$ & at different parameters \\
\hline Poisson, $a$ & $f_{n}^{n}(Z)=\frac{1}{z !} \cdot(n \cdot a)_{i}=M ; D=\sum_{i}^{n} \sigma_{i}^{2}$ & $f_{n}(Z)=(-1)^{n-1} \cdot \prod_{i=1}^{n} \lambda_{i} \cdot \sum_{j=1}^{n} \frac{\exp \left(-\prod_{k \neq j}\left(\lambda_{j}-\lambda_{k}\right)\right.}{k \cdot a)}$ \\
\hline
\end{tabular}

\section{Simulation model to estimate the transportation time in supply chains}

As the analytical dependences applications to estimate the transportation time are limited there is an objective necessity to use other universal tools, for example, the Monte Carlo Method (MCM). It is well known that the MCM use lies in the reproduction of the examined probabilistic mathematical model in the form appropriate "realizations" or "tests". In this work we offer to implement every transportation modelling in the form of the successive realizations set in accordance to the motion route of transport vehicles and in the light of various limitations. Subsequent statistical processing allows us to define the parameters and type of distribution law of delivery time.

In Figure 1 there is a fundamental flow-chart for the transport operations modelling based on the example of the IRT. Let us look at some charts more closely.

In block 1 there is collecting, analysis and systematization of the data of the route, implementation time of transport-logistics operations by different types of transport, delays (customs, control on the road etc.); work modes (warehouses, terminals etc.); traffic schedule (ferry etc.).

In block 2 there is a selection of a transportation mode (unimodal, multimodal and others like that), transport mode (road, marine etc.), and also a route variant (points, distances, customs, frontier transitions etc.).

In block 3 there is a process of forming and checking the indexes of simulation model (laws of travelling time distribution and their parameters; probabilities of experiments connected with limitations according to formula (6) and others).

In blocks 4 and 5 there is a modelling of travelling time during the day, formulas (1) and (2) considering possible limitations and here the decision is made about the stop at point $N$, a limitation (5).

In blocks 6 and 7 there is analysis of collected data about transportation and outages parameters during the $i$-th day transportation to, firstly, check limitations (3), and then to check limitations (4).
In block 8 the duration of drivers rest is modelled (according to the international agreement).

In blocks 9 and 10 all transportation parameters data arrays are formed with taking into account checking the conditions of the transportation ending on the route; the statistic processing and probability evaluation of delivery indexes are held.

It is obvious that while the multimodal transportations modelling is being done, the additional charts get included into the flow chart, which take into account the driving time, the loading/unloading and custom operations and also specific restrictions, for example, regularity (schedule) of ferries departure time etc.

\section{Examples of the JIT delivery fulfilment estimation}

To approve the developed approach the calculations for the different route variants have been done. Taking into account the fact that transportation variants differ in a large variety, to carry out some comparative calculations and clarify the algorithm, two international routes have been chosen: the first one is a unimodal road transportation, the second one is a multimodal transportation (road and marine transport).

All the data, which is necessary for calculation has been collected on the basis of official information (in particular, the data of tachograph, special questionnaires filled in by the drivers, the survey results of the managers who are responsible for the IRT organization). All the modelling results have been put to the statistics processing including:

- verification of extreme values in samples (Arley's and Romanovskiy's criteria);

- statistic characteristics calculation (of the mean values, dispersions) and the distribution laws choosing;

- defining the correlation coefficient between various transport-logistics operations.

Example 1. In Table 4 there is initial data to model the transportation on route 1 . This route includes: departure 


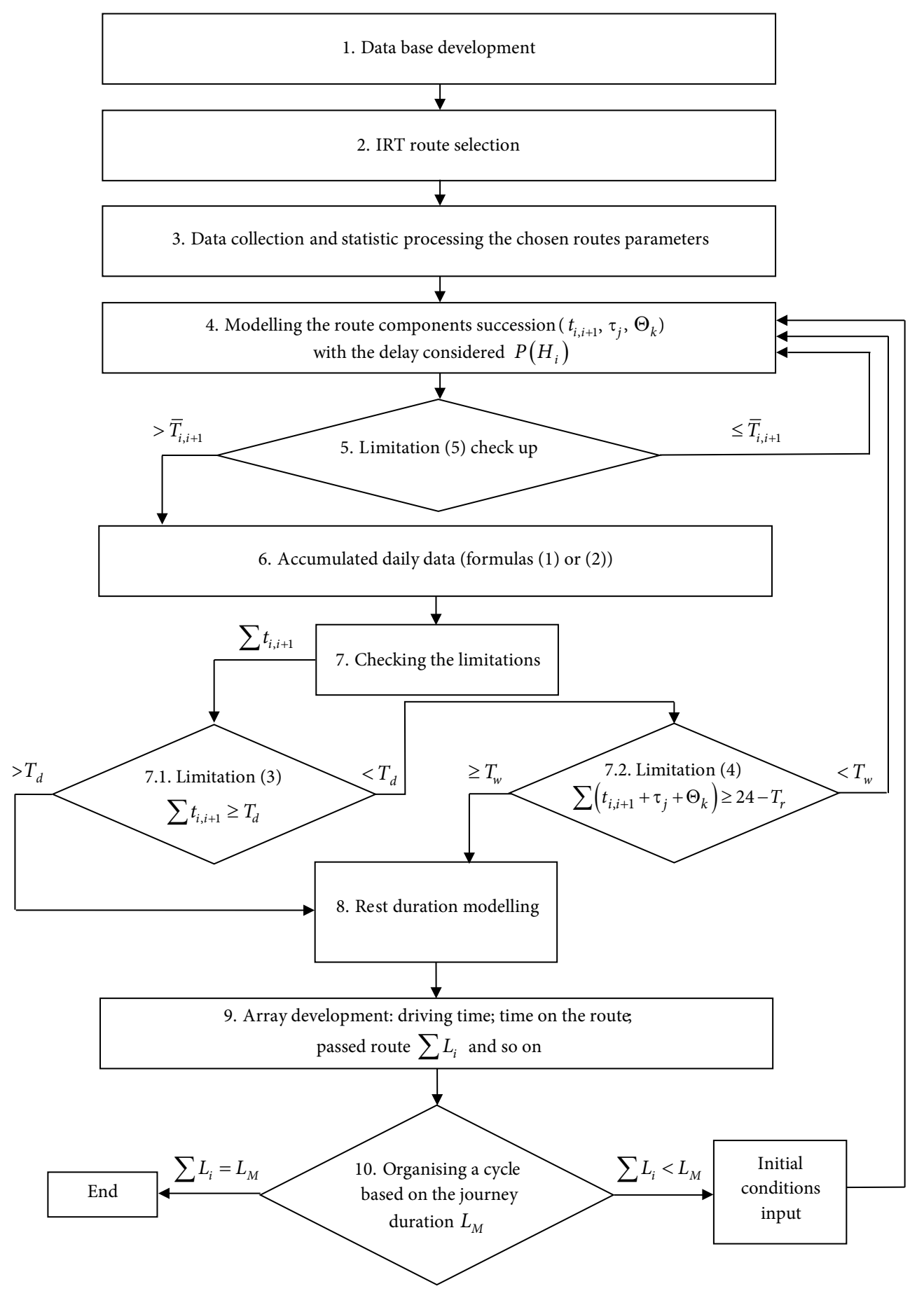

Figure 1. Fundamental flow-chart of transport-logistic operations modelling (based on the IRT)

point A - border B - destination point C (loading at the 24 hours-working warehouse) - border D - unloading E. Table 4 shows us that various distribution laws are used to approximate the statistical data: the normal law is used for the transportation operations connected with driving; the asymmetrical distribution laws, as a rule, are used for the operations connected with border crossing and customs formalities (exponential law, Rayleigh law).

In Tables 5-7 there are results of the statistic processing of the transportation duration on route 1. Predictably, the total delivery time subjects to the normal distribu- tion law. For comparison some calculations have been done using the MCM and dependences for the numerical characteristics for the random variables, formulas (13) and (14). Since the correlation coefficients between the transportation operations were in the limits of $0.1 \ldots 0.15$, the correlation in formula (14) wasn't taken into account. The calculation results were presented in the form of (Table 7): mean $\bar{T}$ values and standard deviations of $\sigma_{T}$; the JIT delivery time with the probability of $P=0.98$ for the modelled distributions and with the approximation of the modelled data by the normal law. 
Table 4. Temporary characteristics of the first route transportation

\begin{tabular}{|l|c|c|l|}
\hline \multicolumn{1}{|c|}{ Route points $^{*}$} & Mean values $[\mathrm{h}]$ & Standard deviation $[\mathrm{h}]$ & \multicolumn{1}{c|}{ Distribution law } \\
\hline Point A - Border B; Dr & 3.8 & 1.0 & Normal \\
\hline Border B; B/C + CC & 1.8 & 1.8 & Exponential (parameter $h=0.55)$ \\
\hline Border B - Point C; Dr & 3.0 & 0.7 & Normal \\
\hline Point C; L + CP & 4.9 & 2.5 & Rayleigh (parameter $\left.\sigma_{r}=3.93\right)$ \\
\hline Point C - Border D; Dr & 4.2 & 1.0 & Normal \\
\hline Border D; B/C + CC & 3.5 & 1.8 & Rayleigh (parameter $\sigma_{r}=2.83$ ) \\
\hline Border D - Point E; Dr & 4.6 & 0.8 & Normal \\
\hline Point E; U+CP & 3.0 & 1.0 & Normal \\
\hline
\end{tabular}

Notes: ${ }^{*} \mathrm{Dr}$ is for driving; $\mathrm{B} / \mathrm{C}+\mathrm{CC}$ are for border and customs control; $\mathrm{L}+\mathrm{CP}$ mean loading and customs procedures; $\mathrm{U}+\mathrm{CP}-\mathrm{un}-$ loading and customs procedures.

Table 5. Distribution function of the delivery time probability (route 1)

\begin{tabular}{|l|c|c|c|c|c|c|c|}
\hline \multirow{2}{*}{\multicolumn{2}{|c|}{ Route characteristics }} & \multicolumn{7}{|c|}{ Upper limit of the interval [h] } \\
\cline { 2 - 10 } & 45 & 50 & 55 & 60 & 65 & 70 & 75 \\
\hline Without delays taken into account & 0.100 & 0.450 & 0.775 & 0.900 & 0.925 & 0.975 & 1.000 \\
\hline With delays taken into account & 0.100 & 0.400 & 0.775 & 0.850 & 0.850 & 0.925 & 1.000 \\
\hline
\end{tabular}

Table 6. Distribution function of the delivery time probability (route 2)

\begin{tabular}{|l|c|c|c|c|c|c|c|}
\hline \multirow{2}{*}{\multicolumn{2}{|c|}{ Route characteristics }} & \multicolumn{7}{|c|}{ Upper limit of the interval [h] } \\
\cline { 2 - 10 } & 65 & 74 & 83 & 92 & 101 & 110 & 119 \\
\hline With lateness taken into account & 0.05. & 0.375 & 0.575 & 0.700 & 0.900 & 1.000 & - \\
\hline With delays and lateness taken into account & 0.05. & 0.350 & 0.525 & 0.675 & 0.875 & 0.975 & 1.000 \\
\hline
\end{tabular}

Table 7. The results of the transportation implementation duration modelling at various routes

\begin{tabular}{|c|c|c|c|c|c|}
\hline Route & $\begin{array}{l}\text { Calculation } \\
\text { method }\end{array}$ & $\begin{array}{c}\text { Mean } \\
\text { values }[\mathrm{h}]\end{array}$ & $\begin{array}{c}\text { Standard } \\
\text { deviation }[\mathrm{h}]\end{array}$ & $\begin{array}{c}\text { Delivery time } \\
\text { (with } P=0.98)[\mathrm{h}]\end{array}$ & $\begin{array}{c}\text { Delivery time } \\
\text { (modelling with } P=0.98)[\mathrm{h}]\end{array}$ \\
\hline 1 & Numerical & 50.7 & 4.1 & 59.1 & - \\
\hline 1 & MCM & 49.5 & 3.5 & 56.7 & 70.4 \\
\hline $\begin{array}{l}1 \\
\text { (with delays taken into } \\
\text { account) }\end{array}$ & $\mathrm{MCM}$ & 52.0 & 7.0 & $66.4^{*}$ & 74.2 \\
\hline 2 & Numerical & 71.0 & 4.7 & 80.6 & - \\
\hline $\begin{array}{l}\text { (with lateness taken into } \\
\text { account) }\end{array}$ & $\mathrm{MCM}$ & 77.5 & 13.0 & $104.0^{*}$ & 109.8 \\
\hline \begin{tabular}{l}
\multicolumn{1}{c}{2} \\
(with delays and lateness \\
taken into account)
\end{tabular} & $\mathrm{MCM}$ & 83.7 & 14.5 & $113^{*}$ & 110.6 \\
\hline
\end{tabular}

Note: ${ }^{*}$ - at approximation by the normal law.

Example 2. Let's examine the variant of the first route, which while being executed had some delays (traffic jams, car accidents, gravimetric parameters control of the road police and others). The carried out analysis has shown that the delays should be regarded as the rare events and the probability of their occurrence in some certain realizations subdues to binomial distribution. So, we can take $P\left(H_{o}\right)=0.9$ and $P\left(H_{1}\right)=0.1$ for the examined route.
As for the delays duration, they can be described by the normal distribution law with the parameters where the average meaning of $\bar{T}_{l}$ is $3.0 \mathrm{~h}$, standard deviation of $\sigma_{l}$ is $0.7 \mathrm{~h}$. The results of modelling are shown in Table 5 . A characteristic feature of this variant is the fact that the total delivery time distribution differs from the normal law due to the "tail" appearance and this reminds of two distributions superposition. 


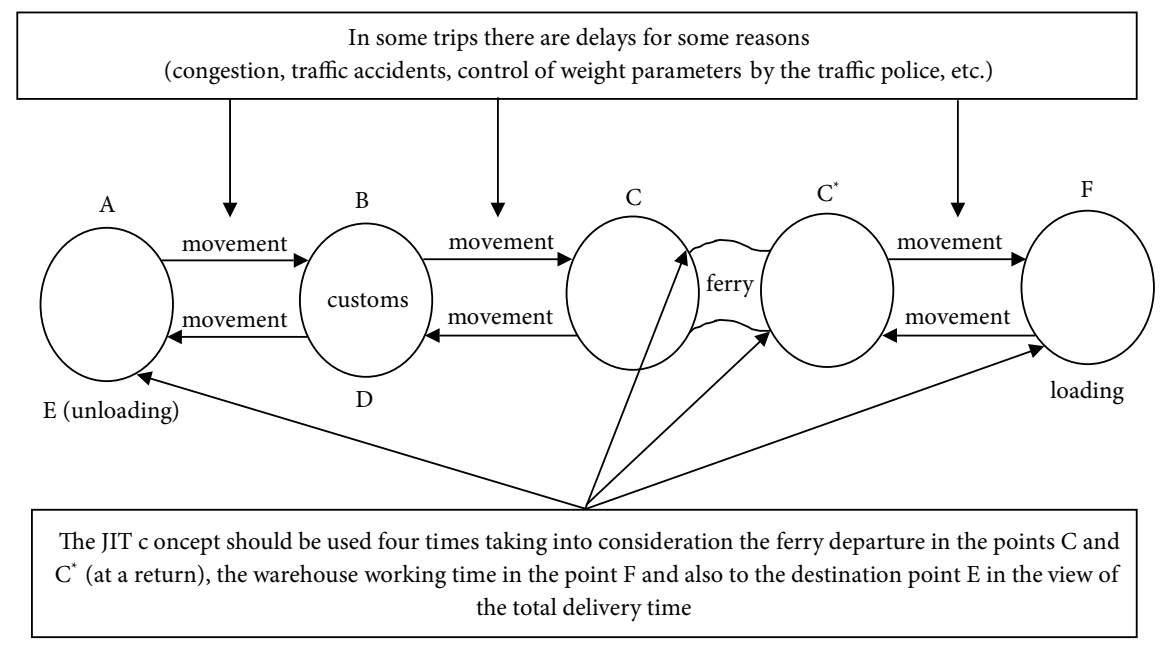

Figure 2. Execution scheme for route 2 (multimodal transportation considering delays and lateness)

Example 3. Let us examine route 2, which is a multimodal transportation that includes road and marine transport. It is important to say that in the point $\mathrm{C}$ a vehicle is placed on a ferry comparing with route 1 . When the ferry arrives at the point $\mathrm{C}^{*}$, the vehicle goes to point $\mathrm{F}$ where it is loaded at the warehouse. Then it returns to the point $\mathrm{C}$ on a ferry and continues driving to the point $\mathrm{E}$ (Figure 2). The peculiarity of this multimodal transportation lies in the fact that ferries depart from the point $\mathrm{C}$ and $\mathrm{C}^{*}$ regularly at 8:00 a.m. and 8:00 p.m. every day according to the timetable while the warehouse works from 9:00 a.m. till 6:00 p.m. The ferry sailing time subdue to the normal law with the parameters where $\bar{T}_{f}=10.3 \mathrm{~h}$ and $\sigma_{f}=1.0 \mathrm{~h}$.

In Table 6 there are the results of modelling, which leads to the conclusion that the deviation from the normal law and more and more distinct display of the distribution superposition are characteristical features for the multimodal transportations. In this table there also are results for route 2 taking into account the delays and lateness.

In the conclusion, we will mark that the calculations results confirm the legitimacy of the hypothesis about possibility of transportation description using random events and variables. Table 7 analysis leads to the conclusion that for some variants especially for unimodal transportations analytical dependences and modelling results give close results. For the combined multimodal transportations taking into account various limitations the preference must be given to the simulation.

The obtained results show that the modelled indexes take into consideration their intercommunication and definitely estimate the supply chains reliability, and this allows decreasing the uncertainty of the logistic system.

\section{Conclusions}

1) The developed methodology allows obtaining the probabilistic estimations of transport operations in the supply chains in accordance with JIT concept. The model differs from the existing empiric ap- proach in the fact that it allows to conduct decompositioning of a transportation process into separate constituents, and to describe them as independent elements with the use of statistical parameters. The next stage of the model development envisages the synthesis of separate transport operations for the transportation process of the set configuration and the following estimation based on the results of casual processes modelling of delivery implementation taking into account JIT concept.

2) To realize the offered approach it is necessary to organize collection, analysis and systematization of materials reflecting statistical nature of executable logistic operations with the purpose of forming the database and its following application in calculations.

3) Application of the developed approach allows describing the transportation process taking into account various limitations (technical, organizational, administrative) and passing to the proved development of events to increase the efficiency of separate operations implementation.

4) The obtained dependences allow getting from the operative management to the situational one in case the vehicle deviates from the planned task being in motion. In turn, it will demand the development of making decision matrix (speed-up border crossing, choosing the toll road, substantial route adjustment, crew replacement etc.) to increase the reliability of JIT transportation implementation. It is necessary to consider possibility of the developed approach application for the different transportation modes, transport modes, route variants in the view of transported goods specific etc. Increasing complication of the processes description, which occur in the logistic systems, connected with the requirement to increase of the supply chains reliability demands the active development of the analytical methods and models based on the information systems and 
information technologies. It is obvious that the developed approach can be used to form the complex model uniting possibilities of software products, GPS (for the QR and adjustment) and the Internet to make effective decisions.

5) The further development of this worked out approach allows us to evaluate the efficiency of transport-logistic operations during the designing and reengineering of SC, to increase the accuracy of costs evaluation connected with transportation, stock management, choice of mediators; besides, along with other concepts (just-in-sequence, QR, LP etc.) it will help to construct the united analytical tools for supply chains management.

\section{References}

Axsäter, S. 2015. Inventory Control. Springer. 268 p. https://doi.org/10.1007/978-3-319-15729-0

Ballou, R. H. 2003. Business Logistics: Supply Chain Management. Prentice Hall. 816 p.

Bazaras, D.; Yatskiv, I.; Mačiulis, A.; Palšaitis, R. 2015. Analysis of common governance transport system development possibilities in the east-west transport corridor, Transport and Telecommunication Journal 16(1): 31-39. https://doi.org/10.1515/ttj-2015-0004

Bifulco, G. N.; Di Pace, R.; Viti, F. 2014. Evaluating the effects of information reliability on travellers' route choice, European Transport Research Review 6(1): 61-70. https://doi.org/10.1007/s12544-013-0110-4

Bowersox, D. J.; Closs, D. J. 1996. Logistical Management: The Integrated Supply Chain Process. McGraw-Hill College. 752 p.

Chalumuri, R. S.; Yasuo, A. 2014. Modelling travel time distribution under various uncertainties on Hanshin expressway of Japan, European Transport Research Review 6(1): 85-92. https://doi.org/10.1007/s12544-013-0111-3

Christopher, M. 2016. Logistics and Supply Chain Management. FT Press. 328 p.

Chopra, S.; Meindl, P. 2015. Supply Chain Management: Strategy, Planning, and Operation. Pearson. 516 p.

Coyle, J. J.; Bardi, E. J.; Langley, C. J. 2002. Management of Business Logistics: A Supply Chain Perspective. South-Western College Pub. 707 p.

Ge, Y.-E.; Prentkovskis, O.; Tang, C.; Saleh, W.; Bell, M.; Junevičius, R. 2015. Solving traffic congestion from the demand side, Promet - Traffic \& Transportation 27(6): 529-538. https://doi.org/10.7307/ptt.v27i6.1734

Heizer, J.; Render, B.; Munson, C. 2016. Operations Management: Sustainability and Supply Chain Management. Pearson. 912 p.

Huber, S.; Klauenberg, J.; Thaller, C. 2015. Consideration of transport logistics hubs in freight transport demand models, European Transport Research Review 7: 32. https://doi.org/10.1007/s12544-015-0181-5

Jonsson, P. 2008. Logistics and Supply Chain Management. McGraw-Hill Education. 510 p.

Kersten, W.; Blecker, T. 2006. Managing Risks in Supply Chains: How to Build Reliable Collaboration in Logistics. Erich Schmidt Verlag. 300 p.

Krajewski, L. J.; Malhotra, M. K.; Ritzman, L. P. 2015. Operations Management: Processes and Supply Chains, Student Value Edition. Pearson. 672 p.
Krüger, N. A.; Vierth, I. 2015. Precautionary and operational costs of freight train delays: a case study of a Swedish grocery company, European Transport Research Review 7: 6. https://doi.org/10.1007/s12544-015-0155-7

Langevin, A.; Riopel, D. 2005. Logistics Systems: Design and Optimization. Springer. 388 p. https://doi.org/10.1007/b106452

Lazauskas, J.; Bureika, G.; Valiūnas, V.; Pečeliūnas, R.; Matijošius, J.; Nagurnas, S. 2012. The research on competitiveness of road transport enterprises: Lithuanian case, Transport and Telecommunication Journal 13(2): 138-147.

https://doi.org/10.2478/v10244-012-0011-y

Lukinskiy, V. S.; Lukinskiy, V. V.; Churilov, R. 2014. Problems of the supply chain reliability evaluation, Transport and Telecommunication Journal 15(2): 120-129.

https://doi.org/10.2478/ttj-2014-0011

Lukinskiy, V. S.; Malevich, Yu.; Plastunyak, I.; Pletnyova, N.; Lukinskiy, V. V. 2007. Modeli i metody teorii logistiki. SanktPeterburg: Piter. 448 s. (in Russian).

Mazurkiewicz, J.; Walkowiak, T. 2013. Discrete transportation system's availability problem in case of critical situation sets, Transport and Telecommunication Journal 14(4): 272-281. https://doi.org/10.2478/ttj-2013-0023

Palšaitis, R.; Petraška, A. 2012. Heavyweight and oversized cargo transportation risk management, Transport and Telecommunication Journal 13(1): 51-56. https://doi.org/10.2478/v10244-012-0005-9

Palšaitis, R.; Ponomariovas, A. 2012. Assessment of rail freight transport service quality, Transport and Telecommunication Journal 13(3): 188-192. https://doi.org/10.2478/v10244-012-0015-7

Petraška, A.; Čižiūnienè, K.; Jarašūnienè, A.; Maruschak, P.; Prentkovskis, O. 2017. Algorithm for the assessment of heavyweight and oversize cargo transportation routes, Journal of Business Economics and Management 18(6): 1098-1114. https://doi.org/10.3846/16111699.2017.1334229

Petraška, A.; Čižiūnienė, K.; Prentkovskis, O.; Jarašūnienė, A. 2018. Methodology of selection of heavy and oversized freight transportation system, Transport and Telecommunication Journal 19(1): 45-58. https://doi.org/10.2478/ttj-2018-0005

Stadtler, H.; Kilger, C. 2008. Supply Chain Management and Advanced Planning: Concepts, Models, Software and Case Studies. Springer. 512 p. https://doi.org/10.1007/b106298

Stock, J.; Lambert, D. 2000. Strategic Logistics Management. McGraw-Hill/Irwin. 896 p.

Vasilis Vasiliauskas, A.; Jakubauskas, G. 2007. Principle and benefits of third party logistics approach when managing logistics supply chain, Transport 22(2): 68-72.

Ventcel', E. S.; Ovcharov, L. A. 1983. Prikladnye zadachi teorii veroyatnostej. Moskva: Radio i svyaz. 416 s. (in Russian).

Wisner, J. D.; Leong, G. K.; Tan, K.-C. 2004. Supply Chain Management: a Balanced Approach. South-Western College Pub. $528 \mathrm{p}$.

Yatskiv, I.; Pticina, I.; Savrasovs, M. 2012. Urban public transport system's reliability estimation using microscopic simulation Transport and Telecommunication Journal 13(3): 219-228. https://doi.org/10.2478/v10244-012-0018-4 